
Not for reproduction, distribution or commercial use.

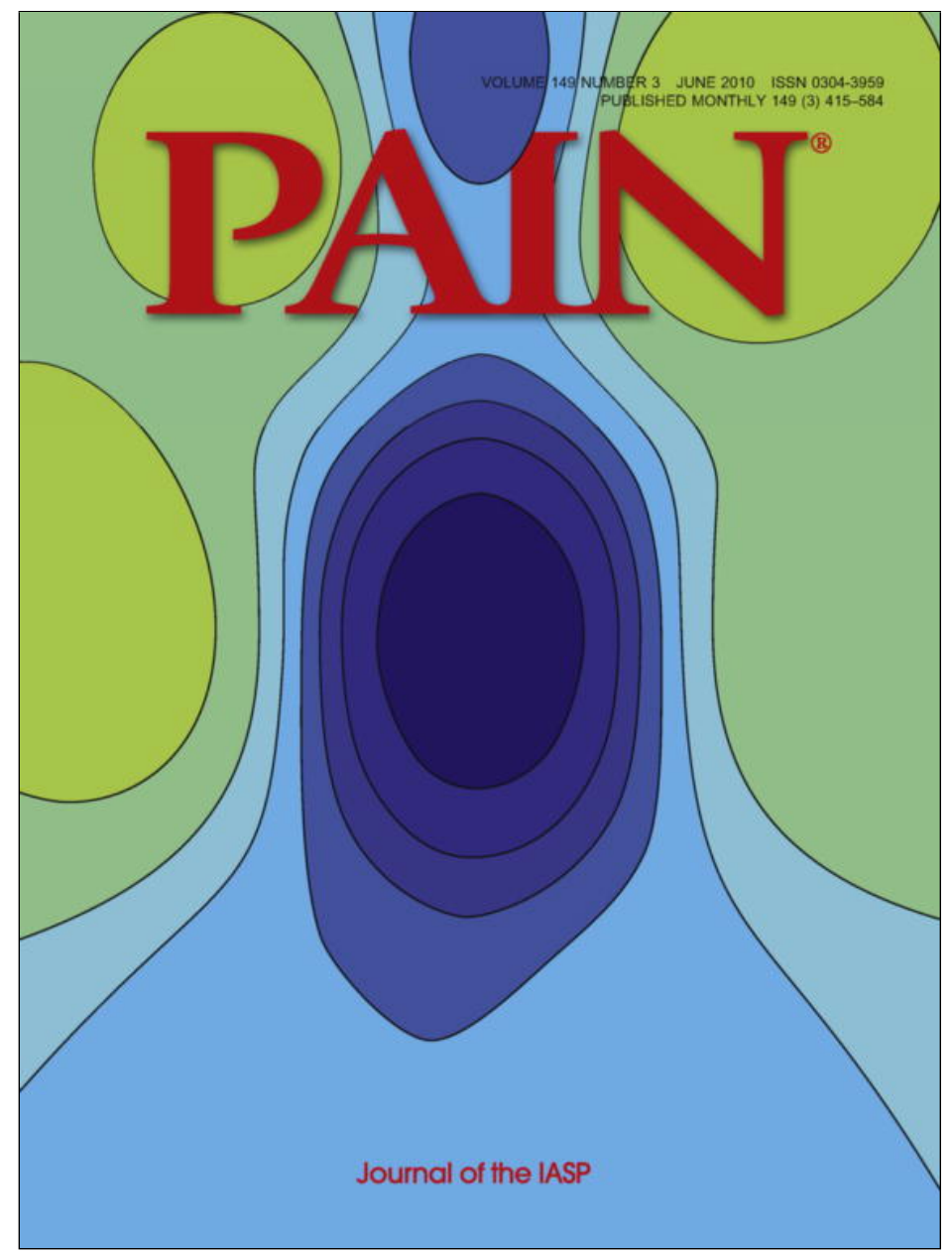

This article appeared in a journal published by Elsevier. The attached copy is furnished to the author for internal non-commercial research and education use, including for instruction at the authors institution and sharing with colleagues.

Other uses, including reproduction and distribution, or selling or licensing copies, or posting to personal, institutional or third party websites are prohibited.

In most cases authors are permitted to post their version of the article (e.g. in Word or Tex form) to their personal website or institutional repository. Authors requiring further information regarding Elsevier's archiving and manuscript policies are encouraged to visit:

http://www.elsevier.com/copyright 
PAIN $^{\circledR} 149(2010) 422-423$

Commentary

\section{Becoming active again? Further thoughts on goal pursuit in chronic pain}

Cognitive-behavioral treatment programs have been developed to give patients with chronic pain the opportunity to reassess their beliefs about the relationship between pain and functioning and to experience that spontaneous safety behaviors - which may be adaptive in acute episodes of pain - are no longer functional when pain lasts for extended periods of time [5]. These treatment programs appear to be useful. Indeed, a recent meta-analysis of randomized controlled trials of these treatments in adults concluded that these treatments have beneficial effects on pain and mood, but also that there is ample room for improvement [3]. It is, for example, recommended that extensive and multimodal programs be replaced by a more targeted approach that focuses on specific treatments for specific outcomes - as has been done in exposurebased techniques targeting pain-related fear [2]. In addition, it is expected that treatments would have stronger effects when treatment content, dose, timing etc. are based on explicit theoretical models. In line with these ideas, a number of authors have recently called for an expanded affective-motivational approach with a prominent focus on behavior in the context of multiple goals $[9,10]$.

In their attempt to resume daily life activities, pain patients engage in several goals, some of which are directly related to dealing with pain (e.g., to avoid further injury, take less medication, increase physical capacity), whereas others are not pain-related (e.g., being professionally successful, meeting other people, losing weight). Interrelations among these multiple goals - either conflicting or facilitating - may have implications for the initiation and maintenance of the intended goal [6]. A particularly stressful situation, for instance, occurs when the goal to satisfy others by resuming work-related activities holds the risk of increasing pain and re-injury. In contrast, the goal to protect bodily integrity by staying home may lead to social rejection. Such a conflict between two avoidance goals is much more difficult to handle than choosing between two attractive options. This situation may result in indecision and oscillation between the two goals, as is often seen in chronic pain patients. Unfortunately, unresolved pain-related goal conflicts may fuel fear [4]. An emerging and intriguing question is whether cognitive-behavioral therapies aimed at the reevaluation of major life goals and at the resolution of enduring goal conflicts help to counter fear-driven and disabling avoidance behavior $[9,10]$.

In line with this novel treatment approach, Christiansen and colleagues (this issue) have developed and evaluated a brief goalpursuit intervention to improve physical capacity through exercising in chronic back pain patients [1]. In order to facilitate the realization of this intended goal, the following strategies were added to a standard back pain treatment (exercise therapy): (1) mental contrasting to increase the patient's expectations about achieving the promoted goal, (2) problem solving techniques to help the patient to overcome obstacles associated with exercising, and (3) implementation intentions to help the patient to prioritize the intended goal in future conflict situations. This intervention led to greater improvements in physical capacity as compared with a standard back pain program, although, unexpectedly, the intervention and control group did not differ in the pain experienced.

To our knowledge, this is the first randomized clinical trial that investigates the efficacy of this specific goal-pursuit treatment in chronic back pain patients, and we think that this novel approach definitely deserves further scientific attention. The paper also raises a number of questions. First, Christiansen et al. focused on strategies that may help to increase the likelihood that pain patients indeed exercise. However, less attention was paid to the assessment of the patient's individual life goals and relations among those goals. During the mental contrasting phase, patients were simply asked to list four positive and four negative aspects associated with exercising, and to further elaborate on half of the listed aspects. They rated the importance of 'improving physical capacity' and their confidence about attaining that goal; other goal dimensions were not rated and neither was the impact of alternative goals. We believe that the intervention may benefit from a more detailed estimation of important life goals and inter-goal relations, as well as from a stronger focus on strengthening facilitative relations between goals (e.g., [6,7]). Second, efficient goal pursuit and behavior change require cognitive and behavioral flexibility. As briefly mentioned by Christiansen et al., chronic pain patients may suffer from weakened executive functioning. An important question is to what extent patients are able to control their cognitions and adapt their behavior in order to deal with current goal conflicts [8]. Third, Christiansen et al. expected that their intervention would enhance physical exercise. However, they did not directly track this goal-directed behavior. They only assessed physical capacity at three points in time, with an increase in the capacity as an indirect estimate of physical exercising. As also discussed by the authors, it would be relevant to identify the number and intensity of daily (exercising) activities. In addition, it would be useful to gain more insight into the patient's specific activity pattern over time and into the effect of the intervention on intergoal relations and goal pursuit. In Christiansen et al.'s study, it is unclear, for example, whether patients experienced less goal conflicts after the intervention. An interesting avenue for future studies would be the application of computerized diaries and ecological momentary assessment methods to examine patients' dynamic goal pursuit in daily life.

In conclusion, the study by Christiansen et al. is important as it is probably the first in a series of novel cognitive-behavioral treatments in chronic pain that have the potential to better help patients pursue their daily life goals. 


\section{Conflict of interest}

The authors have no conflicts of interest relating to this commentary.

\section{References}

[1] Christiansen S, Oettingen G, Dahme B, Klinger R. A short goal-pursuit intervention to improve physical capacity: A randomized clinical trial in chronic back pain patients. Pain 2010;149:444-52.

[2] De Peuter S, De Jong JR, Crombez G, Vlaeyen JW. The nature and treatment of pain-related fear in chronic musculoskeletal pain. Cogn Behav Psychother 2009;23:85-103.

[3] Eccleston C, Williams AC, Morley S. Psychological therapies for the management of chronic pain (excluding headache) in adults. Cochrane Database Syst Rev 2009:CD007407.

[4] Karoly P, Okun MA, Ruehlman LS, Pugliese JA. The impact of goal cognition and pain severity on disability and depression in adults with chronic pain: An examination of direct effects and mediated effects via pain-induced fear. Cogn Ther Res 2008;32:418-33.

[5] Keefe FJ, Rumble ME, Scipio CD, Giordano LA, Perri LM. Psychological aspects of persistent pain: current state of the science. J Pain 2004;5:195-211.

[6] Riediger M, Freund AM. Interference and facilitation among personal goals: differential associations with subjective well-being and persistent goal pursuit. Pers Soc Psychol Bull 2004;30:1511-23.
[7] Riediger M, Freund AM. Focusing and restricting: two aspects of motivational selectivity in adulthood. Psychol Aging 2006;21:173-85.

[8] Solber Nes L, Roach A, Segerstrom SC. Executive functions, self-regulation, and chronic pain: a review. Ann Behav Med 2009;37:173-83.

[9] Van Damme S, Crombez G, Eccleston C. Coping with pain: a motivational perspective. Pain 2008;139:1-4.

[10] Vlaeyen JW, Crombez G, Linton SJ. The fear-avoidance model of pain: We are not there yet. Comment on Wideman et al. "A prospective sequential analysis of the fear-avoidance model of pain" [Pain, 2009] and Nicholas "First things first: reduction in catastrophizing before fear of movement" [Pain, 2009]. Pain 2009;146:222. author reply 222-223.

Martien G.S. Schrooten Johan W.S. Vlaeyen ${ }^{*}$

Department of Psychology, Research Group Health Psychology, University of Leuven, Tiensestraat, 102, B 3000 Leuven,

Belgium

Department of Clinical Psychological Science, Research Group Behavioural Medicine, Maastricht University, P.O. Box 616, 6200 MD Maastricht, The Netherlands 